\title{
Anatomical Examination of the Foramens of the Middle Cranial Fossa
}

\author{
Examinación Anatómica de los Forámenes de la Fosa Craneal Media
}

\author{
Nadire Unver Dogan*; Zeliha Fazlıgulları*; Ismihan Ilknur Uysal*; Muzaffer Seker* \& Ahmet Kagan Karabulut*
}

UNVER DOGAN, N.; FAZLIOGULLARI, Z.; UYSAL, I. I.; SEKER, M. \& KARABULUT, A. K. Anatomical examination of the foramens of the middle cranial fossa. Int. J. Morphol., 32(1):43-48, 2014.

SUMMARY: Three foramina can be identified in the greater wing of the sphenoid bone: The foramen rotundum (FR), foramen ovale (FO) and foramen spinosum (FS). In addition, there may be another foramen called foramen ovale accessorium or foramen vesalius (FV) which connects the middle cranial fossa to the fossa pterygoidea (pterygoid fossa). It is described as an opening with smooth walls in front and medial to foramen ovale which leads to an oblique channel directed towards the fossa pterygoidea. FV was present between FO and FR in 14 (31.8\%) of 44 dry and 6 (33.3\%) of 18 cadaver skullbase sides (total 20 (32.3\%) of 62). The diameter values of foramens on both the right and the left side were observed to be almost symmetrical. FR's distance from the midline on the left side was greater than the right side. Also, the distance between FO and the petrous apex and the distance between FS and the petrous apex were greater on the left side. On the right side the distance between FO and FR, and the distance between FO and FS were greater. Also, the distance between FR and the petrous apex was greater on the right side. Anatomical variations in appearance size and distance of FR, FO, FS and FV are of great surgical importance. In conclusion, we can infer that the information provided with this study can help the neurosurgeon and anatomist to increase the knowledge about anatomy of middle cranial fossa.

KEY WORDS: Foramen rotundum; Foramen ovale; Foramen spinosum; Foramen Vesalius.

\section{INTRODUCTION}

Three foramina can be identified in the greater wing of the sphenoid bone (Standring, 2005). The foramen rotundum (FR) is generally $3.4 \mathrm{~mm}$ long (Sondheimer, 1971; Ginsberg et al., 1994) and situated just below and behind the medial end of the superior orbital fissure, and leads forwards into the pterygopalatine fossa, to which it conducts the maxillary nerve. Posterolateral to the foramen rotundum (FR) is the foramen ovale (FO) which transmits the mandibular nerve. Behind the FO is the foramen spinosum (FS), which transmits the middle meningeal artery (Standring). It is generally 2 to $4 \mathrm{~mm}$ long with an average diameter approximately 1.5 to $3.62 \mathrm{~mm}$ (Yanagi, 1987; Ginsberg et al.). In addition, there may be another foramen called foramen ovale accessorium or foramen vesalius (FV) which connects the middle cranial fossa to the pterygoid fossa. It was described as an opening with smooth walls in front and medial to FO which leads to an oblique channel directed towards the pterygoid fossa. The canal was opened near the root of the pterygoid process. It is generally known that an emissary vein "vein of vesalius" transmits through FV which the cavernous sinus and pterygoid plexus communicate (Lanzieri et al., 1988; Gupta et al., 2005). However, a small nerve (nervoulus sphenoidalis lateralis) may also pass through foramen into cavernous sinus (Gupta et al.).

The importance of evaluating the skull base foramina has been demonstrated in the literature (Lanzieri et al.; Gupta et al.; Ray et al., 2005; Shinohara et al., 2010). A variety of neoplastic processes and trigeminal neuralgia have been documented to involve the FO and FR (Lanzieri et al.; Kanpolat et al., 2001, Kaplan et al., 2007). However, wide review of the literature shows only very few studies on the anatomical variations of FO, FR, FS and FV. To establish some preliminary data on the dimensions and anatomical variation of these foramens in dried and cadaver human skulls we conducted the present study.

"Department of Anatomy, Faculty of Medicine, Selcuk University, Konya, Turkey. 


\section{MATERIAL AND METHOD}

Forty-four dry and 18 adult cadaver skullbase sides were considered for the present anatomic study. These skulls were obtained from preserved sets of bones received at Department of Anatomy, Meram Medical Faculty, Selcuk University, Konya, Turkey.

Adult fresh cadaveric skullbases were used for microsurgical dissection. Sixteen adult skullbase vaults and brains were removed and the heads were embalmed in $10 \%$ formalin solution. Two adult skull base sides were used as fresh cadaver.

The duramater of the middle cranial fossa was stripped off the bone in a lateral to medial direction and anteriorly to the superior orbital fissure. The periostal bridge, formed by the union of the periostal dura with the periorbita just over the superior orbital fissure, was separated by sharp dissection, thereby the superficial layer of the dura propria covering the lateral wall of the cavernous sinus was dissected posteriorly. The deeper layer of the dura propria overlying the cranial nerves located within the lateral wall of the cavernous sinus. Gasserian ganglion and the mandibular branch and maxillary of the trigeminal nerve were exposed. The duramater on the petrous bone was lifted up, protecting the greater superficial petrosal nerve in its sulcus. After cutting off the branches of the trigeminal nerve, the base of the middle cranial fossa were all exposed.

Maximum length and width of FO, FR, FS, FV and the distances between these nerves were measured for each specimen. In addition, the distances between these foramens and the petrous apex, posterior clinoid process, anterior clinoid process and middle line were measured.

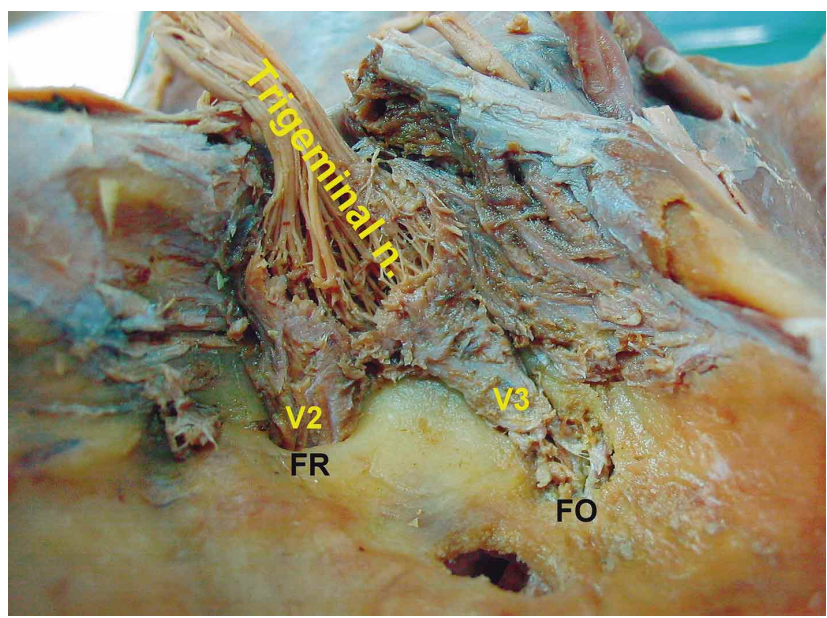

Fig. 1. N. maxillaris (V2) passed from foramen rotundum (FR) and n. mandibularis (V3) passed from foramen ovale (FO) in a cadaver skull base.
Measurements were taken by $0.01 \mathrm{~mm}$ sensitive digital caliper by the same researcher. The measurement values were given as Mean \pm SD. Student's t test was used for statistical analysis.

\section{RESULTS}

It was observed that maxillary nerve passed from FR, mandibular nerve passed from FO (Figs. 1 and 2) and middle meningeal artery passed from FS in all of the specimens. These three foramens were determined in all skull bases. The measurement values of these foramens are given in Tables I, II and III. Accordingly, the diameter values of foramens on both the right and the left side were observed to be almost symmetrical. FR's distance from the midline on the left side was greater than the right side. Also, the distance between FO and the petrous apex and the distance between FS and the petrous apex were greater on the left side. On the right side the distance between FO and FR, and the distance between FO and FS were greater. Also, the distance between FR and the petrous apex was greater on the right side.

FV was present between FO and FR in 14 (31.8\%) of 44 dry (Figs. 3 and 4 ) and 6 (33.3\%) of 18 cadaver skullbase sides (total $20(32.3 \%)$ of 62) (Fig. 2). It was bilateral in 5 skullbases (Fig. 4) and unilateral in 10 skullbases (7 right and 3 left) (Figs. 2 and 3). The average length of FV was 5.41 2.64 (Mean $\pm \mathrm{SD}$ ). The maximum longitudinal and tranverse diameters of $\mathrm{FV}$, the distance of $\mathrm{FV}$ to midline, apex partis petrosa, proc. clinoideus posterior, FR and FO were measured and minimum, maximum, average and standard deviation values were evaluated for both skullbase sides (Table IV).

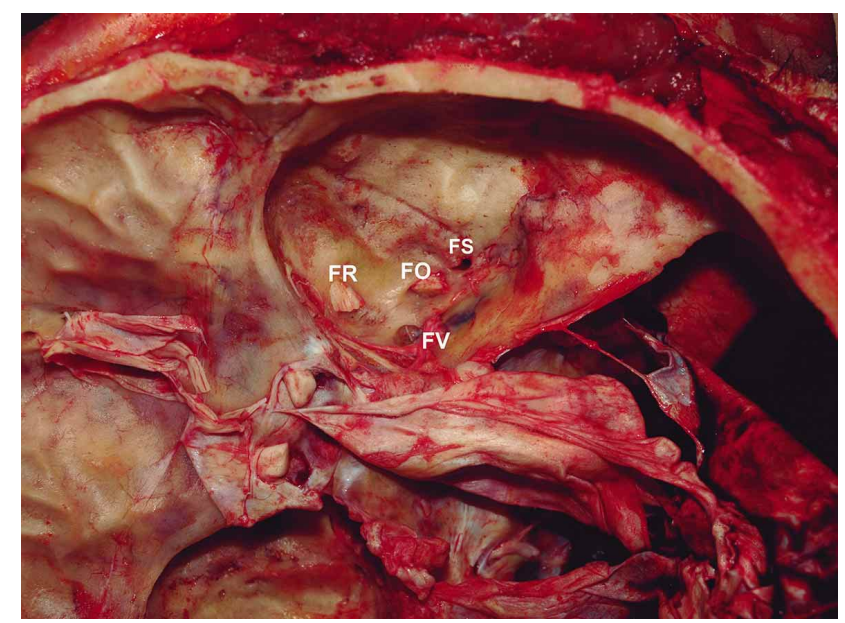

Fig. 2. N. maxillaris (V2) passed from foramen rotundum (FR) and n. mandibularis (V3) passed from foramen ovale (FO), foramen spinosum (FS) and a foramen vesalius (FV) in a fresh cadaver skull base. 
Table I. Longitudinal (LDFR) and tranverse (TDFR) diameters, the distance to midline (FRMidline), the distance to apex partis petrosa (FR-Apex) and Proc. clinoideus anterior (FRPCA) of foramen rotundum in right and left sides (Minimum-maximum, mean \pm standard deviation).

\begin{tabular}{lcccc}
\hline & \multicolumn{2}{c}{ Right } & \multicolumn{2}{c}{ Left } \\
\cline { 2 - 5 } & Min-Max & Mean \pm SD & Min-Max & Mean \pm SD \\
\hline LDFR & $3.93-5.01$ & $4.48 \pm 1.15$ & $4.04-4.68$ & $4.36 \pm 0.66$ \\
TDFR & $2.90-3.77$ & $3.34 \pm 0.92$ & $3.10-3.61$ & $3.36 \pm 0.54$ \\
FR-Midline & $16.78-19.21$ & $17.99 \pm 2.59$ & $17.40-19.66$ & $18.53 \pm 2.41$ \\
FR-Apex & $17.17-21.17$ & $19.17 \pm 3.61$ & $15.34-21.06$ & $18.20 \pm 4.94$ \\
FR-PCA & $9.06-12.69$ & $10.88 \pm 3.65$ & $10.25-12.28$ & $11.27 \pm 2.09$ \\
\hline
\end{tabular}

Table II. Longitudinal (LDFO) and tranverse (TDFO) diameters, the distances to midline (FO-Midline), to apex partis petrosa (FO-Apex), to Proc. clinoideus posterior (FO-PCP), to foramen rotundum (FR) and to foramen spinosum (FS) of foramen ovale in right and left sides (Minimum-maximum, mean \pm standard deviation)

\begin{tabular}{lcccc}
\hline & \multicolumn{2}{c}{ Right } & \multicolumn{2}{c}{ Left } \\
\cline { 2 - 5 } & $\begin{array}{c}\text { Min-Max } \\
(\mathbf{m m})\end{array}$ & $\begin{array}{c}\text { Mean } \pm \text { SD } \\
(\mathbf{m m})\end{array}$ & $\begin{array}{c}\text { Min-Max } \\
(\mathbf{m m})\end{array}$ & $\begin{array}{c}\text { Mean } \pm \text { SD } \\
(\mathbf{m m})\end{array}$ \\
\hline LDFO & $6.46-7.91$ & $7.18 \pm 1.78$ & $6.91-7.66$ & $7.29 \pm 0.94$ \\
TDFO & $3.75-4.89$ & $4.32 \pm 1.41$ & $3.79-4.32$ & $4.06 \pm 0.66$ \\
FO-Midline & $21.42-23.74$ & $22.58 \pm 2.99$ & $21.22-23.09$ & $22.15 \pm 2.41$ \\
FO-Apex & $7.58-10.87$ & $9.22 \pm 3.90$ & $8.41-11.40$ & $9.91 \pm 3.54$ \\
FO-PCP & $14.36-19.17$ & $16.76 \pm 4.51$ & $13.93-17.46$ & $15.69 \pm 3.42$ \\
FO-FR & $8.66-11.89$ & $10.28 \pm 3.55$ & $7.70-10.65$ & $9.18 \pm 3.15$ \\
FO-FS & $2.14-3.62$ & $2.88 \pm 1.74$ & $2.26-3.27$ & $2.76 \pm 1.22$ \\
\hline
\end{tabular}

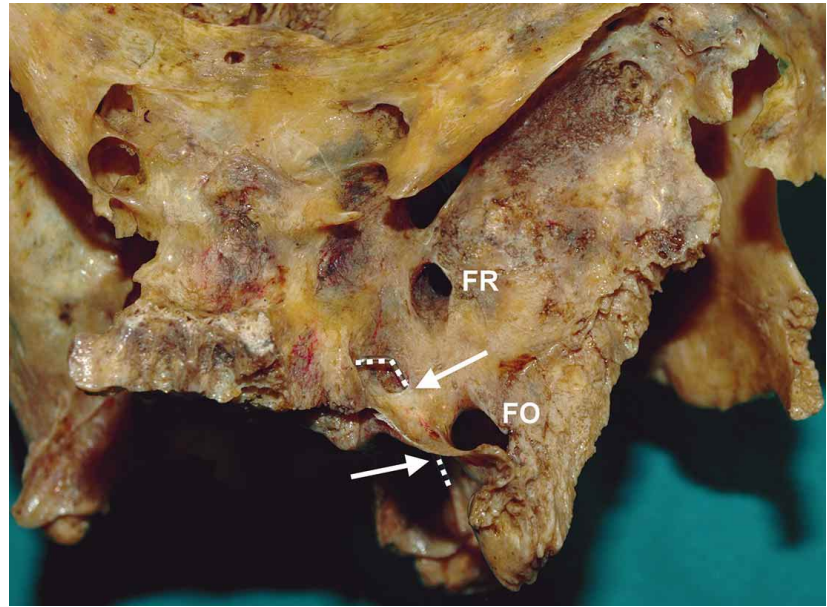

Fig. 3. Foramen rotundum (FR), foramen ovale (FO) and foramen vesalius $(\mathrm{FV})$ at greater wing of sphenoidal bone.

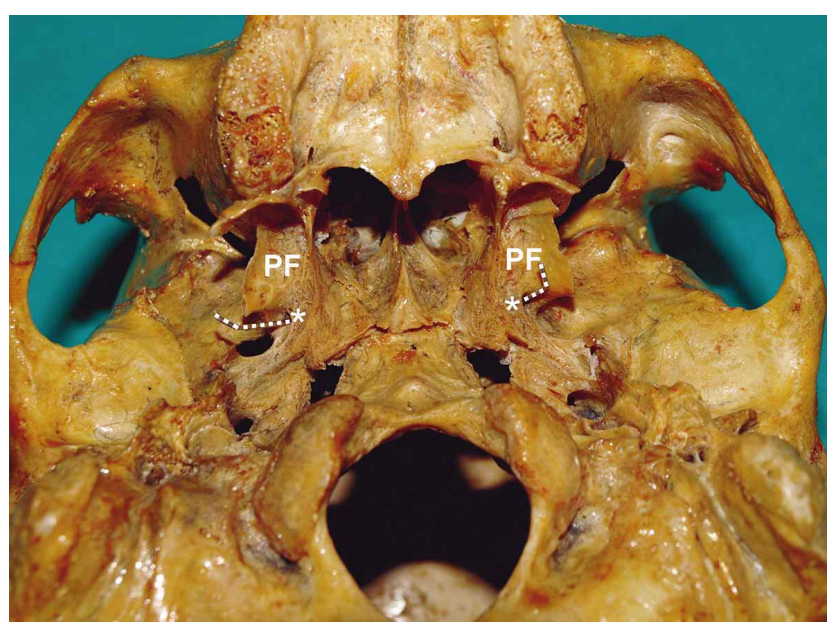

Fig. 4. Outer ostium of FV (*) at pterygoid fossa (PF). 
Table III. Longitudinal (LDFS) and tranverse (TDFS) diameters, the distance to midline (FSMidline), the distance to apex partis petrosa (FS-Apex) and Proc. clinoideus posterior (FSPCP) of foramen spinosum in right and left sides (Minimum-maximum, mean \pm standard deviation).

\begin{tabular}{lcccc}
\hline & \multicolumn{2}{c}{ Right } & \multicolumn{2}{c}{ Left } \\
\cline { 2 - 5 } & $\begin{array}{c}\text { Min-Max } \\
(\mathbf{m m})\end{array}$ & $\begin{array}{c}\text { Mean } \pm \text { SD } \\
(\mathbf{m m})\end{array}$ & $\begin{array}{c}\text { Min-Max } \\
(\mathbf{m m})\end{array}$ & $\begin{array}{c}\text { Mean } \pm \text { SD } \\
(\mathbf{m m})\end{array}$ \\
\hline LDFS & $2.40-3.41$ & $2.90 \pm 1.19$ & $2.62-3.18$ & $2.90 \pm 0.67$ \\
TDFS & $1.72-2.07$ & $1.90 \pm 0.41$ & $1.81-2.21$ & $2.01 \pm 0.47$ \\
FS-Midline & $27.36-29.86$ & $28.61 \pm 2.96$ & $27.24-29.69$ & $28.47 \pm 2.97$ \\
FS-Apex & $9.87-13.28$ & $11.58 \pm 3.84$ & $11.60-14.92$ & $13.26 \pm 3.74$ \\
FS-PCP & $20.33-26.10$ & $23.22 \pm 4.77$ & $19.10-24.61$ & $21.85 \pm 5.16$ \\
\hline
\end{tabular}

Table IV. Longitudinal (LDFV) and tranverse (TDFV) diameters, the distance to midline (FVMidline), the distance to apex partis petrosa (FV-Apex), proc. clinoideus posterior (FV-PCP), the distance to foramen rotundum (FV-FR) and the distance to foramen ovale of foramen vesalius in right and left sides (Minimum-maximum, mean \pm standard deviation)

\begin{tabular}{lcccc}
\hline & \multicolumn{2}{c}{ Right } & \multicolumn{2}{c}{ Left } \\
\cline { 2 - 5 } & Min-Max & Mean \pm SD & Min-Max & Mean \pm SD \\
\hline LDFV & $1.89-2.79$ & $2.32 \pm 0.73$ & $1.83-3.37$ & $2.60 \pm 0.92$ \\
TDFV & $1.00-1.63$ & $1.31 \pm 0.49$ & $0.90-1.84$ & $1.37 \pm 0.56$ \\
FV-Midline & $15.32-17.88$ & $16.60 \pm 2.01$ & $15.79-1.54$ & $17.67 \pm 2.23$ \\
FV-Apex & $4.68-8.72$ & $6.70 \pm 2.82$ & $5.18-10.85$ & $8.02 \pm 3.06$ \\
FV-PCP & $12.15-16.37$ & $14.26 \pm 2.94$ & $7.57-12.47$ & $10.02 \pm 2.65$ \\
FV-FR & $5.61-12.81$ & $9.21 \pm 5.03$ & $4.89-12.41$ & $8.65 \pm 3.58$ \\
FV-FO & $2.65-6.19$ & $4.42 \pm 2.78$ & $1.90-3.69$ & $2.80 \pm 1.06$ \\
\hline
\end{tabular}

\section{DISCUSSION}

As FO is one of the important foramens which lies between intracranial and extracranial structures, it is used for diagnostic and therapeutic invasive approaches (Yanagi; Gupta et al.; Ray et al.; Reymond et al., 2005). For this reason, the knowledge of morphologic and topographic features of FO is important. There are different results in the literature which evaluates the diameters of $\mathrm{FO}$ in different races. The average maximal length of $\mathrm{FO}$ was reported 7.48 $\mathrm{mm}$ in a developmental study performed in 220 specimens of Japan race (Yanagi), $7.2 \mathrm{~mm}$ in a German study (Lang et al., 1984) and 7.46 in a study performed in Nepal (Ray et $a l$.$) . The average maximal length of FO was higher in the$ left side $(7.29 \pm 0.94 \mathrm{~mm})$ than the right side $(7.18 \pm 1.78 \mathrm{~mm})$ side but there wasn't a statistical significance $(\mathrm{P}>0.05)$ between two sides like similar studies in the literature (Yanagi; Ray et al.). The average distance of FO to the midline was similar on both sides $(22.58 \pm 2.99$ on the right side, $22.15 \pm 2.41$ on the left side) in our study.

A more common variant of the FR is as known "lateral rotundal canal" the presence of a small (1 to $3 \mathrm{~mm}$ ) opening in the floor of this foramen, which leads to the infratemporal fossa or to the space between the pterygoid plates. In anatomic dissections, Sondheimer detected these openings in five of 50 skulls and speculated that they transmitted emissary veins (Ginsberg et al.). Ginsberg et al., reported this variation's ratio as $16 \%$ but it was not observed in our cadaver specimens. 
Kocaogullar et al. (2003) reported that the average diameter of FR was 3.11 in cadaver specimens, 3.44 in skulls and there was not a statistical significance betweenright and left in a study of 52 specimens (cadaver and skull). In this study, there wasn't statistical significance $(\mathrm{P}>0.05)$ between both sides in the average longitudinal diameters $(4.48 \pm 1.15$ $\mathrm{mm}$ in the right, $4.36 \pm 0.66 \mathrm{~mm}$ in the left) and average transverse diameters.

Knowledge of topography and of the changeability of the position of the FO and FR is important during operations of the cavernal sinus, performed by the lateralapproach, which enables some complications to be avoided, injury of the trigeminal nerve. It also limits of the internal carotid artery, which is important in maintaining the haemodynamic control during operations of the internal carotid artery (Teul et al., 2002).

Congenital variants of the FS are generally related to defects in osteogenesis or to maldevelopment of the middle meningeal artery (Ginsberg et al.). Medial defect (26.8\%), asymmetry (16\%), duplication (only rare cases) or absence of FS (3.2\%) are reported as variations in the literature (Ginsberg et al.). In this study, the average maximal length of FS was $2.90 \pm 1.19 \mathrm{~mm}$ in the right and $2.90 \pm 0.67 \mathrm{~mm}$ in the left. There wasn't statistical significance between right and left side $(\mathrm{P}>0.05)$ and the variations reported in the literature were not observed in this study.

Vesalius in his famous book, "De humani corporis fabrica" describes FV with uncommonly subjective language and according to Vesalius, this foramen rarely seen in one side of the skull, and much more rarely still on both sides and no remarkable difference was observed between left and right sides. A wide incidence rate of FV (17\%-79.7\%) was reported in the literature (Lanzieri et al.; Ginsberg et al.; Kodama et al., 1997; Kocaogullar et al.; Reymond et al.; Gupta et al.; Shinohara et al.). Although, in some of these studies (Ginsberg et al.; Reymond et al.; Gupta et al.) it was reported that FV was generally observed unilateral, Kodama et al. reported that it was bilateral in $75.36 \%$ of the cases. In the cases which $\mathrm{FV}$ was unilateral, it was reported that FV was observed more frequently in the right (Gupta et al., Ginsberg etal.), in the left (Reymond et al.) or there were no difference between two sides (Kodama et al.). In this study, FV was observed in 20 (32.3\%) of 62 skullbase sides. It was unilateral in $75 \%$ and $60 \%$ was in the right side. The importance of $\mathrm{FV}$ lies in the fact that it gives passage to vein of vesalius, an emissary vein. Emissary veins are those which link the intracranial venous sinuses with veins outside the cranial cavity. They pass through the potential space between galea aponeurotica and pericranium (Gupta et al.). They are of importance in that they are channels along which infected thrombus can reach the inferior of cranial cavity from outside it. Surgical importance of FV lies in the fact that during percutaneous trigeminal rhizotomy, needle insertion through the FV the caversous sinus puncture may occur and has been described in eight cases with temporal lobe hematoma reported (Håkanson, 1981; Gupta et al.). Therefore, the knowledge about the symmetry and incidence of FV is not only important from the anatomical point of view but is also essential for the operating surgeon.

FV is not seen in all the individuals but when present, it is very unlikely to misinterpret a normal well formed foramen as abnormal (Gupta et al.). Variations in the FV can be also explained by developmental reasons, because the sphenoid bone has a complex embryologic development, and the FV is one site of embryologic fusion in the spheoid bone (Gupta et al.; Shinohara et al.).

Anatomical variations in appearance size and distance of FR, FO, FS and FV are of great surgical importance. In conclusion, we can infer that the information provided with this study can help the neurosurgeon and anatomist to increase the knowledge about anatomy of middle cranial fossa.

UNVER DOGAN, N.; FAZLIOGULLARI, Z.; UYSAL, I. I.; SEKER, M. \& KARABULUT, A. K. Examinación anatómica de los forámenes de la fosa craneal media. Int. J. Morphol., 32(1):43-48, 2014.

RESUMEN: Tres forámenes pueden ser identificados en el ala mayor del esfenoides: El foramen redondo (FR), foramen oval (FO) y el foramen espinoso (FS). Puede además existir otro foramen llamado foramen oval accesorio o foramen de Vesalio (FV), que conecta la fosa craneal media a la fosa pterigoidea. Se describe como una abertura con paredes lisas por anterior y medial al foramen oval, que conduce a un canal oblicuo dirigido hacia la fosa pterigoidea. FV estuvo presente entre FO y FR en 14 (31,8\%) de 44 cráneos secos y 6 (33,3\%), en 18 lados en la base de cráneos de cadáveres (total 20 (32,3\%) de 62). El diámetro de los forámenes en los lados derecho e izquierdo se observó casi simétricos. Las distancias de FR desde la línea mediana en el lado izquierdo fue mayor que en el lado derecho. Además, la distancia entre FO y el vértice de la porción petrosa y la distancia entre el FS y el vértice porción petrosa fueron mayores en el lado izquierdo. En el lado derecho la distancia entre A y FR, así como la distancia entre A y FS fueron mayores. Por otra parte, la distancia entre los FR y el vértice del porción petrosa fue mayor en el lado derecho. Las variaciones anatómicas en el tamaño de la apariencia y la distancia de FR, DE, FS y FV son de gran importancia quirúrgica. Podemos inferir que la información proporcionada en este estudio puede ayudar al neurocirujano y anatomista para aumentar el conocimiento sobre la anatomía de la fosa craneal media. 


\section{REFERENCES}

Ginsberg, L. E.; Pruett, S. W.; Chen, M. Y. \& Elster, A. D. Skullbase foramina of the middle cranial fossa: reassessment of normal variation with high-resolution CT. AJNR Am. J. Neuroradiol., 15(2):283-91, 1994.

Gupta, N.; Ray, B. \& Ghosh, S. Anatomic characteristics of foramen vesalius. Kathmandu Univ. Med. J. (KUMJ), 3(2):155-8, 2005.

Håkanson, S. Trigeminal neuralgia treated by the injection of glycerol into the trigeminal cistern. Neurosurgery, 9(6):63846, 1981.

Kanpolat, Y.; Savas, A.; Bekar, A. Y. \& Berk, C. Percutaneous controlled radiofrequency trigeminal rhizotomy for the treatment of idiopathic trigeminal neuralgia: 25-year experience with 1,600 patients. Neurosurgery, 48(3):524-32, 2001.

Kaplan, M.; Erol, F. S.; Ozveren, M. F.; Topsakal, C.; Sam, B. \& Tekdemir, I. Review of complications due to foramen ovale puncture. J. Clin. Neurosci., 14(6):563-8, 2007.

Kocaogullar, Y.; Avci, E.; Fossett, D. \& Caputy, A. The extradural subtemporal keyhole approach to the sphenocavernous region: anatomic considerations. Minim. Invasive Neurosurg., 46(2):100-5, 2003.

Kodama, K; Inoue, K; Nagashima, M.; Matsumura, G.; Watanabe, S. \& Kodama, G. Studies on the foramen vesalius in the Japanese juvenile and adult skulls. Hokkaido Igaku Zasshi, 72(6):667-74,1997.

Lang, J.; Maier, R. \& Schafhauser, O. Postnatal enlargement of the foramina rotundum, ovale et spinosum and their topographical changes. Anat. Anz., 156(5):351-87, 1984.

Lanzieri, C. F.; Duchesneau, P. M.; Rosenbloom, S. A.; Smith, A. S. \& Rosenbaum, A. E. The significance of asymmetry of the foramen of Vesalius. AJNR Am. J. Neuroradiol., 9(6):1201-4, 1988.

Ray, B.; Gupta, N. \& Ghose, S. Anatomic variations of foramen ovale. Kathmandu Univ. Med. J. (KUMJ), 3(1):64-8, 2005.

Reymond, J.; Charuta, A. \& Wysocki, J. The morphology and morphometry of the foramina of the greater wing of the human sphenoid bone. Folia Morphol. (Warsz), 64(3):188-93, 2005.

Standring, S. M. Gray's Anatomy. 39th ed. Newyork, Elsevier/ Churchill Livinstone, 2005. pp.462-6.

Shinohara, A. L.; de Souza Melo, C. G.; Silveira, E. M.; Lauris, J. R; Andreo, J. C. \& de Castro Rodrigues, A. Incidence, morphology and morphometry of the foramen of Vesalius: complementary study for a safer planning and execution of the trigeminal rhizotomy technique. Surg. Radiol. Anat., 32(2):159-64, 2010

Sondheimer, F. K. Basal foramina and canals. In: Newton, T. H.; Potts, D. G. (Eds.). Radiology of the skull and brain. St. Louis, Mosby, 1971.

Teul, I.; Czerwinski, F.; Gawlikowska, A.; Konstanty-Kurkiewicz, V. \& Slawinski, G. Asymmetry of the ovale and spinous foramina in mediaeval and contemporary skulls in radiological examinations. Folia Morphol. (Warsz), 61(3):147-52, 2002.

Yanagi, S. Developmental studies on the foramen rotundum, foramen ovale and foramen spinosum of the human sphenoid bone. Hokkaido Igaku Zasshi, 62(3):485-96, 1987.

Correspondence to:

Nadire Unver Dogan

Selcuk University

Faculty of Medicine

Department of Anatomy

Konya

TURKEY

Phone: +9003322415000

Fax: +9003322412181

Email: nunver2003@yahoo.com

Received: 13-02-2011

Accepted: 24-12-2013 